\title{
Can Tumbling without Brine Improve Tenderness and Proteolysis of Beef Loin Muscles?
}

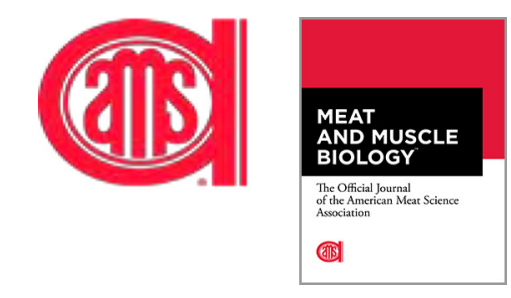

\author{
Jacob R. Tuell ${ }^{1}$, Qianqian Yu², and Yuan H. Brad Kim* \\ ${ }^{1}$ Meat Science and Muscle Biology Laboratory, Department of Animal Sciences, Purdue University, \\ West Lafayette, IN 47907, USA \\ ${ }^{2}$ College of Food Science and Nutritional Engineering, China Agricultural University, Haidian District, \\ Beijing 100083, PR China \\ *Corresponding author. Email: bradkim@purdue.edu (Yuan H. Brad Kim)
}

\begin{abstract}
Tumbling of intact muscle foods has been widely applied to processed meats using brine solution. However, the use of tumbling without brine on fresh beef muscles has not been fully examined. Therefore, this study aimed to evaluate fresh beef tumbling on meat quality and proteolytic features of loin (longissimus lumborum) muscles. Moreover, interactions with the duration of postmortem aging were investigated. Loins $(n=9)$ at $7 \mathrm{~d}$ postmortem were sectioned and allocated among 2 tumbling (T) treatment groups at 60 (T60) or 90 (T90) min, as well as a nontumbled control (T0) group. After treatment, subsections were made and divided among 0,7 , or $14 \mathrm{~d}$ of further aging. Meat quality was assessed by shear force values, water-holding ability, and color attributes. The extent of proteolysis was determined by quantification of desmin and troponin-T, myofibril fragmentation index (MFI), and transmission electron microscopy. An interaction between fresh beef tumbling and aging duration was observed in shear force values $(P=0.032)$. At $0 \mathrm{~d}$, muscles from T90 exhibited lower shear force $(21.6 \mathrm{~N})$ compared with T0 $(34.8 \mathrm{~N})$ and T60 $(24.7 \mathrm{~N})$ groups. Muscles from T60 and T90 groups maintained lower shear force than T0 controls at each respective aging duration. Higher cooking loss $(P=0.011)$ but not purge loss $(P=0.412)$ was observed in the T60 and T90 groups compared with T0. Shear force results were supported by higher MFI in T60 and T90 groups than T0 controls $(P<0.001)$, as well as the disappearance of intact troponin-T with further aging $(P=0.009)$. Transmission electron microscopy supported increased initial tenderness was primarily caused by physical disruptions to myofibrillar structure, though fresh beef tumbling may facilitate proteolysis with further aging.
\end{abstract}

Key words: instrumental tenderness, meat tumbling, muscle ultrastructure, postmortem proteolysis, transmission electron microscopy

Meat and Muscle Biology 5(1): 45, 1-11 (2021)

doi:10.22175/mmb.13044

Submitted 17 August 2021

Accepted 17 September 2021

\section{Introduction}

Tenderness is one of the primary sensory attributes that dictates the overall palatability of fresh beef (O'Quinn et al., 2018; Miller, 2020; Warner et al., 2020). It has been assessed that if tenderness is rated to be unacceptable, there would be a $69 \%$ chance that a consumer will deem overall palatability to be unacceptable as well (O'Quinn et al., 2018). Several studies have supported that consumers will pay a premium for beef with known tenderness (Boleman et al., 1997;
Miller et al., 2001; Shackelford et al., 2001). Accordingly, understanding the mechanisms by which tenderness can be affected is critical to ensuring consistent product quality. Tenderness is primarily influenced by the integrity of the myofibrils, sarcomere length, and connective tissues (Warner et al., 2020), though the contribution of each can differ by individual muscle (Rhee et al., 2004). For the beef longissimus lumborum et thoracis muscle, Warner-Bratzler shear force (WBSF) values are moderately correlated with the amount of connective tissue and degradation 
of desmin (a marker of proteolysis) and weakly correlated with sarcomere length (Rhee et al., 2004). Although the US beef industry has shown marked improvements in fresh beef quality and consistency in recent decades (Voges et al., 2007; Guelker et al., 2013; Martinez et al., 2017; Gonzalez and Phelps, 2018), meeting consumer expectations for eating quality, especially tenderness, remains critical.

Several postharvest strategies have been used to improve tenderness of fresh beef, though the ability to accomplish this without negatively impacting other quality attributes or sensory traits is often limited. For example, mechanical tenderization is commonly applied to improve tenderness of beef by physically disrupting muscle structure through penetration with blades or needles. Although mechanical tenderization can be effective at improving tenderness, this often comes at the expense of other eating quality traits, including juiciness and flavor (Glover et al., 1977; Jeremiah et al., 1999), which are also crucial to the overall palatability of beef (O'Quinn et al., 2018). Tenderization methods that penetrate the meat may introduce foodborne pathogens (Luchansky et al., 2008), leading consumers to express concerns regarding the safety of such products (Yang et al., 2021). Consequently, this may lead consumers to cook mechanically tenderized beef products to a higher degree of doneness (Yang et al., 2021), which would be expected to negatively impact palatability to an extent (McKillip et al., 2017).

Meat tumbling has been widely implemented for processed meat applications to improve eating quality and enhance the pickup of brine solutions. During the tumbling process, physical disruptions to the muscle structure occur through contact with the rotating drum and other pieces of meat (Martin, 2001). In general, the tenderness of tumbled muscle foods increases with the duration of tumbling (Dzudie and Okubanjo, 1999; Pietrasik and Shand, 2004; Moon et al., 2007). However, it is poorly understood how quality of fresh beef would be affected through the application of tumbling without the use of a brine solution. Recently, Morrow et al. (2019) observed no positive effect of tumbling without brine on tenderization of beef rectus abdominus muscles. However, beef tenderization is known to be muscle-specific (Juárez et al., 2010; Kim et al., 2018b; Nair et al., 2019), and the flank muscle is often described as tougher than the loin owing to larger muscle fibers and higher amount of connective tissue (Jeremiah et al., 2003; Couvreur et al., 2019). As physical disruptions to myofibrillar structure could enhance the activity of proteolytic enzymes (Kim et al., 2018a;
Kim et al., 2018b; Setyabrata and Kim, 2019; Setyabrata et al., 2019), it stands to reason that tumbling with further aging could be an effective strategy of tenderization in certain muscles. We hypothesized that tumbling fresh beef loin muscles without brine would improve tenderization through physical disruptions to muscle structure, enhanced proteolysis with further aging, or some interaction between those factors.

\section{Materials and Methods}

\section{Raw materials and processing}

Beef loins (longissimus lumborum; $n=9$; USDA Select grade) were obtained from a commercial processor with 3 loins at one processing date and the remaining 6 at a later date, each from different carcasses. The loins were stored in vacuum packaging at $2{ }^{\circ} \mathrm{C}$ until $7 \mathrm{~d}$ postmortem. At $7 \mathrm{~d}$, loins were divided into 3 equal length sections averaging 1.75 \pm 0.05 (standard error) $\mathrm{kg}$ per section and assigned to tumbling treatments at 60 (T60) or 90 (T90) min or nontumbled control (T0). Treatments were applied in a balanced complete block design for equal distribution among muscle position to account for locational differences throughout the loin muscle (Rhee et al., 2004). Sections were vacuum sealed in 2 layers of 3-mil thickness vacuum packaging (CLARITY, Bunzl Processor Division, Riverside, MO), and weights were recorded prior to packaging. Tumbling for each respective duration was performed within a Lance LT-30 $500 \mathrm{lb}$ capacity meat tumbler (Lance Industries, Hartford, WI) at $8.5 \mathrm{rpm}$. Following tumbling, samples were removed from the packaging, gently blotted with a paper towel, and reweighed. Sections from the T0 group were packaged for a similar duration as the treatment groups to account for purge loss induced from vacuum packaging. Each section was then further cut into 3 equal length subsections, repackaged, and randomly allocated among aging durations of 0 (no further aging), 7 , or $14 \mathrm{~d}$ at $2{ }^{\circ} \mathrm{C}$. One additional steak $(2.54 \mathrm{~cm}$ thickness $)$ was collected from each subsection from the $0 \mathrm{~d}$ further aging group for instrumental color measurement over $7 \mathrm{~d}$ of simulated retail display as later described. At the completion of each respective aging duration, steaks (2.54 cm thickness) were made to determine cooking loss and shear force, whereas remaining muscle samples for biochemical analyses were frozen and stored at $-80{ }^{\circ} \mathrm{C}$. 


\section{Water-holding ability}

Water-holding ability of beef muscles was indirectly assessed by purge, display, and cooking losses (Setyabrata and Kim, 2019). Purge loss was assessed as the percentage weight loss before and after tumbling and further aging. Display loss was determined on $0 \mathrm{~d}$ further aged samples only as the weight loss before and after $7 \mathrm{~d}$ of aerobic display storage. Cooking loss was assessed by cooking the samples on an open-faced electric griddle (Model GR-150, Cuisinart, Stamford, $\mathrm{CT}$ ) set at $135{ }^{\circ} \mathrm{C}$. A type-T thermocouple (Omega Engineering, Norwalk, CT) was used to monitor internal temperature, and steaks were flipped at $41^{\circ} \mathrm{C}$ and cooked until $71{ }^{\circ} \mathrm{C}$ was reached. After 30 min of resting at room temperature, the steaks were gently blotted and reweighed. The percent difference between raw and cooked weights was calculated as cooking loss.

\section{Instrumental display color}

Steaks ( $2.54 \mathrm{~cm}$ thick) from the $0 \mathrm{~d}$ further aging group were displayed for $7 \mathrm{~d}$ at $2{ }^{\circ} \mathrm{C}$ on polystyrene foam trays with polyvinylchloride overwrap film $\left(23,000 \mathrm{~cm}^{3} \mathrm{O}^{2} / \mathrm{m}^{2} / 24 \mathrm{~h}\right.$ at $\left.23{ }^{\circ} \mathrm{C}\right)$. Lighting was provided by fluorescent bulb at approximately 1,450 lx (OCTRON T8 Lamps, Wilmington, MA). A colorimeter (HunterLab MiniScan EZ, Reston, VA) was used to measure Commission Internationale de 1'Eclairage (CIE) $L^{*}$ (lightness), CIE $a^{*}$ (redness), and CIE $b^{*}$ (yellowness) values at 1,4 , and $7 \mathrm{~d}$ of aerobic display. Three readings were taken per steak at each time point and pooled prior to statistical analysis. The colorimeter was equipped with a $25-\mathrm{mm}$ diameter measuring device, illuminant $\mathrm{A}$, and degree observer of $10^{\circ}$. The degree of discoloration was determined by hue angle, and color saturation (chroma) values were calculated from CIE $a^{*}$ and CIE $b^{*}$ in accordance with American Meat Science Association guidelines (AMSA, 2012).

\section{Warner-Bratzler shear force}

Steaks used for cooking loss measurement were individually wrapped in foil and stored at $4{ }^{\circ} \mathrm{C}$ for $16 \mathrm{~h}$. WBSF measurement was conducted according to American Meat Science Association guidelines (AMSA, 2015). Cores (1.27-cm diameter; at least 6 per steak) were collected by cutting parallel to fiber direction, avoiding visible connective tissue and fat. Shear force was measured using a texture analyzer (TA-XT Plus Texture Analyser, Stable Micro Systems Ltd., Godalming, Surrey, UK) with WBSF
V-shaped blade attachment. Cores were sheared perpendicular to fiber direction, and peak shear force (N) was recorded. Prior to statistical analysis, the mean shear force per sample was determined.

\section{Myofibril fragmentation index}

Fragmentation of myofibrils was assessed in duplicate using the myofibril fragmentation index (MFI) protocol of Culler et al. (1978) with some modification. Approximately $4 \mathrm{~g}$ of scissor-minced sample was homogenized in a 1:10 (w/v) ratio with MFI buffer (100 mM potassium chloride, $20 \mathrm{mM}$ potassium phosphate, $1 \mathrm{mM}$ egtazic acid, $1 \mathrm{mM}$ magnesium chloride, and $1 \mathrm{mM}$ sodium azide $\mathrm{pH} 7.0$ ) at $2{ }^{\circ} \mathrm{C}$ for $45 \mathrm{~s}$. The homogenate was centrifuged at $1,000 \times g$ for $15 \mathrm{~min}$, after which the supernatant was discarded. The pellet was resuspended in $40 \mathrm{~mL}$ of MFI buffer. The centrifugation and removal of supernatant was repeated. After resuspending the pellet in $10 \mathrm{~mL}$ of MFI buffer, the sample was strained to remove connective tissue. An additional $10 \mathrm{~mL}$ of MFI buffer was used to pass myofibrils through the strainer. Afterwards, protein concentration of the filtrate was quantified by comparison with known bovine serum albumin standards to dilute the samples to a concentration of $0.5 \mathrm{mg} / \mathrm{mL}$. A ultraviolet spectrophotometer (VWR UV-1600 PC, VWR International, Radnor, PA) was used to measure absorbance at $540 \mathrm{~nm}$, and MFI was determined by multiplying the absorbance value by 200 .

\section{Whole muscle protein extraction, sodium dodecyl sulphate-polyacrylamide gel electrophoresis, and western blotting}

Extraction of muscle proteins was conducted using the protocol of Kim et al. (2010) with modifications described by Setyabrata et al. (2019). Sodium dodecyl sulphate-polyacrylamide gel electrophoresis load checks were conducted to ensure consistent protein concentration. Western blotting procedures were performed in accordance with Setyabrata et al. (2019). Briefly, 15\% bis-acrylamide (100:1) separating gel with 5\% stacking gel was loaded with $40 \mu \mathrm{g}$ of protein, and electrophoresis was conducted for $3 \mathrm{~h}$ at $130 \mathrm{~V}$ (Bio-Rad PowerPac Basis, Bio-Rad Laboratories, Hercules, CA). The transfer of proteins to transfer membranes (IPVH00010, Millipore, Billerica, MA) was conducted for $90 \mathrm{~min}$ at $90 \mathrm{~V}$ in Tris-glycine buffer. Blocking was conducted for $1 \mathrm{~h}$ at room temperature with $5 \%(\mathrm{w} / \mathrm{v})$ nonfat dry milk in phosphate buffer saline-tween (PBST). Incubation for $16 \mathrm{~h}$ at $4{ }^{\circ} \mathrm{C}$ with a $1: 20,000$ dilution of monoclonal mouse 
anti-desmin (D1022, Sigma Aldrich, St. Louis, MO) or a 1:40,000 dilution of anti-troponin-T (T6277, Sigma Aldrich) in 3\% (w/v) nonfat dry milk in PBST was applied. After 3 washes in PBST, a 1:20,000 (desmin) or 1:15,000 dilution (troponin-T) of monoclonal goat anti-mouse immunoglobulin $\mathrm{G}(\mathrm{H}+\mathrm{L})$ horseradish peroxidase conjugate (170-6516, Bio-Rad Laboratories) in 3\% (w/v) nonfat dry milk in PBST was applied for $1 \mathrm{~h}$ at room temperature. The washing steps were repeated prior to imaging. Imaging was conducted by developing membranes with enhanced chemiluminescence reagents (Thermo Fisher Scientific, Waltham, MA) and visualizing with a ChemiDoc-It ${ }^{\mathrm{TS} 2}$ imager (UVP, Upland, CA). Intact and degradation bands were quantified by comparison of band intensity with the intact band of an internal reference sample (each same $\mathrm{T} 0$ control at $0 \mathrm{~d}$ further aging).

\section{Muscle ultrastructure}

Muscle ultrastructure was assessed by transmission electron microscopy (TEM). Representative samples per tumbling and aging treatment combination were collected parallel to fiber direction, approximately $2 \mathrm{~cm}$ from the exterior of the section. Samples were stored in $2.5 \%$ glutaraldehyde buffer at $4{ }^{\circ} \mathrm{C}$ until fixation. Samples were rinsed 3 times in $0.1 \mathrm{M}$ cacodylate buffer prior to fixation with $1 \%$ osmium tetroxide with $0.8 \%$ ferricyanide. Dehydration was conducted through a series of ethanol dilutions $(50 \%, 75 \%, 95 \%, 100 \% \times$ 3 ), after which samples were immersed in acetonitrile and acetonitrile with Spurr's resin $(2: 1[\mathrm{v} / \mathrm{v}]$ followed by $1: 2[\mathrm{v} / \mathrm{v}])$. Samples were embedded in $100 \%$ Spurr's resin for $2 \mathrm{~h}$ at $50{ }^{\circ} \mathrm{C}$. Microtomy was performed to ensure samples were parallel to muscle fiber direction. Samples were embedded on copper TEM grids, and imaging was performed (Tecnai T12, FEI Company, Hillsboro, OR) at 11,500× magnification. Images were viewed with Gatan DigitalMicrograph software (v.3.31. 2360.0, Gatan, Inc., Pleasanton, CA).

\section{Statistical analysis}

The design of this experiment was a balanced complete block design with a factorial arrangement of 3 tumbling durations (T0, T60, T90) by 3 further aging durations $(0 \mathrm{~d}, 7 \mathrm{~d}, 14 \mathrm{~d})$. Data were analyzed with the PROC GLIMMIX procedure of SAS (9.4; SAS Institute, Cary, NC). Fresh beef tumbling and aging durations were considered as fixed effects with each carcass serving as a block. Color data were analyzed as a split-plot with tumbling duration as whole plot and display day as subplot. Means were separated by least significant differences with statistical significance set at $P<0.05$. Pearson correlation coefficients were determined using the PROC CORR procedure. No effect of processing date was found for any attribute $(P>0.05)$ and thus was omitted from the final statistical model.

\section{Results and Discussion}

\section{Water-holding ability}

Multiple weight loss measurements, including the purge loss of beef sections and cooking and display weight losses of beef steaks, were used to assess water-holding ability. No significant tumbling impact on purge loss of beef sections was found $(P=0.412$; Table 1). Further aging increased purge losses, wherein an additional $14 \mathrm{~d}$ aging induced the highest purge loss from beef samples followed by 7 and $0 \mathrm{~d}$ aging $(P<$ 0.001). For cooking loss of steaks, fresh beef tumbling resulted in more weight loss during cooking at $24.9 \%$ and $26.0 \%$ for T60 and T90, respectively, compared with $22.9 \%$ for the T0 controls $(P=0.011)$. Aging

Table 1. Effect of fresh beef tumbling and further aging on water-holding capacity attributes of beef loins $(n=9)$

\begin{tabular}{|c|c|c|c|c|c|c|c|c|c|c|}
\hline & \multicolumn{5}{|c|}{ Fresh beef tumbling duration (min) } & \multicolumn{5}{|c|}{ Further aging (days) } \\
\hline & T0 & T60 & T90 & SEM & $\begin{array}{l}\text { Significance } \\
\text { of } P \text { value }\end{array}$ & $0 \mathrm{~d}$ & $7 \mathrm{~d}$ & $14 \mathrm{~d}$ & SEM & $\begin{array}{c}\text { Significance } \\
\text { of } P \text { value }\end{array}$ \\
\hline Purge loss (\%) & 1.60 & 1.77 & 1.84 & 0.17 & 0.412 & $0.48^{\mathrm{z}}$ & $2.15^{\mathrm{y}}$ & $2.58^{\mathrm{x}}$ & 0.17 & $<0.001$ \\
\hline Cooking loss (\%) & $22.9^{\mathrm{b}}$ & $24.9^{\mathrm{a}}$ & $26.0^{\mathrm{a}}$ & 2.7 & 0.011 & 24.8 & 24.7 & 24.3 & 2.7 & 0.885 \\
\hline Display weight loss (\%) & 2.24 & 2.47 & 2.57 & 0.50 & 0.362 & & & & & \\
\hline
\end{tabular}

$\mathrm{SEM}=$ standard error of the mean

No two-way interactions between fresh beef tumbling and aging duration were significant $(P>0.05)$.

${ }^{\mathrm{a}, \mathrm{b}}$ Means lacking a common superscript within a row differ due to fresh beef tumbling duration $(P<0.05)$.

${ }^{\mathrm{x}-\mathrm{z}}$ Means lacking a common superscript within a row differ due to further aging duration $(P<0.05)$. 
had no impact on cooking loss $(P=0.885)$, nor was there any interaction between tumbling and aging observed for both cooking and purge losses $(P=$ 0.710 ). Display weight loss over $7 \mathrm{~d}$ of simulated retail display was assessed on steaks from $0 \mathrm{~d}$ further aged beef sections only, where no effect of tumbling was found $(P=0.362)$.

As most published studies regarding tumbling are associated with the addition of brine solution, information regarding how tumbling without brine would influence water-holding of fresh meat products is less available. Several tumbling studies utilizing a brine solution have found positive tumbling impacts on waterholding attributes of muscle foods (Boles and Shand, 2002; Pietrasik and Shand, 2004; Moon et al., 2007). These effects are known to be dependent upon factors including tumbling duration and speed (Lin et al., 1990; Dzudie and Okubanjo, 1999; Pietrasik and Shand, 2004; Moon et al., 2007). Ockerman et al. (1978) reported no changes in final yield and moisture loss through short-term tumbling $(30 \mathrm{~min})$, whereas improvements in tenderness and cohesiveness of cured cooked hams were found. Conversely, Pietrasik and Shand (2004) found a decrease in purge loss of cooked beef roast when extended tumbling $(16 \mathrm{~h})$ with brine enhancement was applied. The results of the present study indicate that although no brine solution is included, tumbling of beef loins would have minimal effects on immediate purge loss after tumbling, and further purge loss during aging would not be induced. Further, no adverse tumbling impact on display weight loss of fresh beef steaks was found, though this attribute was assessed in the $0 \mathrm{~d}$ further aged group only. As water-holding is highly dependent on the extramyofibrillar fraction of water (Pearce et al., 2011; Warner, 2017), it may be that the tumbling conditions used in the present study would have a negligible effect on mobilizing this fraction. However, an increase in cooking loss of steaks from tumbled beef sections was observed. As most previous tumbling research has added brine solution, which would be expected to affect the solubility and functionality of muscle proteins, the effects of tumbling only are presently poorly categorized. Various factors are known to contribute water loss during cooking, including shrinkage of the protein network and denaturation of muscle proteins (Warner, 2017). It could be postulated that tumbling would result in larger gaps between cooked muscle fibers, resulting in more cooking loss (Pearce et al., 2011). Morrow et al. (2019) found cooking loss of beef rectus abdominus muscles tumbled without brine to be higher relative to the nontumbled control, in agreement with the findings in the present study. However, despite increased cooking loss, moisture content of both the raw and cooked products were equivalent, and consumer juiciness scores between tumbled without brine and control muscles were comparable (Morrow et al., 2019). As the correlation between cooking loss and sensory juiciness of the longissimus lumborum et thoracis is weak (Rhee et al., 2004), further understanding of how tumbling would affect juiciness of beef loin steaks would be warranted.

\section{Instrumental display color}

No interactions between tumbling treatments and display day were observed for any color attribute $(P>0.05$; Table 2$)$. Fresh beef tumbling resulted in lower CIE $a^{*}(P<0.001)$ and CIE $b^{*}(P<0.001)$ values compared with the T0 controls, whereas no differences between T60 and T90 were found $(P>$ $0.05)$. Accordingly, chroma values of tumbled steaks were lower than the control group $(P<0.001)$. No differences in CIE $L^{*}(P=0.429)$ or hue angle values $(P=0.994)$ across treatments were observed. Values for CIE $a^{*}$, CIE $b^{*}$, and chroma values decreased with display duration $(P<0.05)$, which could be expected as color deteriorates during aerobic display (Suman and Joseph, 2013). The increase in hue angle with

Table 2. Effect of fresh beef tumbling duration and display day on instrumental color attributes of beef loins $(n=9)$

\begin{tabular}{|c|c|c|c|c|c|}
\hline & CIE $L^{*}$ & CIE $a^{*}$ & CIE $b^{*}$ & Hue angle & Chroma \\
\hline \multicolumn{6}{|l|}{$T^{1}$} \\
\hline T0 & 36.2 & $26.6^{\mathrm{a}}$ & $20.5^{\mathrm{a}}$ & 37.6 & $33.6^{\mathrm{a}}$ \\
\hline T60 & 35.9 & $24.6^{\mathrm{b}}$ & $19.0^{\mathrm{b}}$ & 37.6 & $31.1^{b}$ \\
\hline T90 & 35.9 & $24.1^{\mathrm{b}}$ & $18.6^{\mathrm{b}}$ & 37.6 & $30.5^{b}$ \\
\hline SEM & 0.7 & 0.5 & 0.4 & 0.3 & 0.7 \\
\hline \multicolumn{6}{|l|}{$D^{2}$} \\
\hline $1 \mathrm{~d}$ & 36.2 & $27.2^{\mathrm{x}}$ & $20.8^{\mathrm{x}}$ & 37.4 & $34.2^{\mathrm{x}}$ \\
\hline $4 \mathrm{~d}$ & 36.0 & $25.0^{y}$ & $19.2^{\mathrm{y}}$ & 37.5 & $31.5^{y}$ \\
\hline $7 \mathrm{~d}$ & 35.8 & $23.2^{z}$ & $18.1^{\mathrm{z}}$ & 38.0 & $29.4^{z}$ \\
\hline SEM & 0.7 & 0.5 & 0.4 & 0.3 & 0.7 \\
\hline \multicolumn{6}{|c|}{ Significance of $P$ value } \\
\hline$T$ & 0.429 & $<0.001$ & $<0.001$ & 0.994 & $<0.001$ \\
\hline$D$ & 0.250 & $<0.001$ & $<0.001$ & 0.051 & $<0.001$ \\
\hline$T \times D$ & 0.061 & 0.343 & 0.950 & 0.383 & 0.678 \\
\hline \multicolumn{6}{|c|}{$\mathrm{SEM}=$ standard error of the mean. } \\
\hline \multicolumn{6}{|c|}{${ }^{1}$ Tumbling duration effect. } \\
\hline \multicolumn{6}{|c|}{${ }^{2}$ Display period effect. } \\
\hline \multicolumn{6}{|c|}{$\begin{array}{l}\text { a,b Means lacking a common superscript within a column differ due to } \\
\text { resh beef tumbling duration }(P<0.05) \text {. }\end{array}$} \\
\hline \multicolumn{6}{|c|}{$\begin{array}{l}{ }^{\mathrm{x}-\mathrm{z}} \text { Means lacking a common superscript within a column differ due to } \\
\text { further aging duration }(P<0.05) \text {. }\end{array}$} \\
\hline
\end{tabular}


display was just outside of statistical significance $(P=$ $0.051)$, and CIE $L^{*}$ values did not change during display $(P=0.250)$. As color was measured on $0 \mathrm{~d}$ further aged samples only due to limitations in sample size, any effect further aging may have on color stability of tumbled beef cannot be fully determined. Considering the decreased CIE $a^{*}, \mathrm{CIE} b^{*}$, and chroma values, it would be expected that tumbling would result in some initial oxidation or denaturation of sarcoplasmic proteins. As cooking loss of beef is generally not affected by sarcoplasmic proteins (Purslow et al., 2016), the effects of tumbling on cooking loss would likely be better explained by the disruptions to myofibrillar structures than denaturation of sarcoplasmic proteins. Regardless, additional study regarding how tumbling without brine would affect functionality and denaturation of myofibrillar and sarcoplasmic proteins would be needed. As tumbling has been shown to be exacerbate oxidative processes (Cheng and Ockerman, 2003; Bombrun et al., 2014), which may be compounded by poorer oxidative stability with extended aging (Kim et al., 2018b), understanding the interactive effects of fresh beef tumbling with aging duration would also be warranted.

\section{Warner-Bratzler shear force}

There was an interaction $(P=0.032$; Figure 1) between tumbling and further aging durations for WBSF values. Tumbling resulted in an immediate

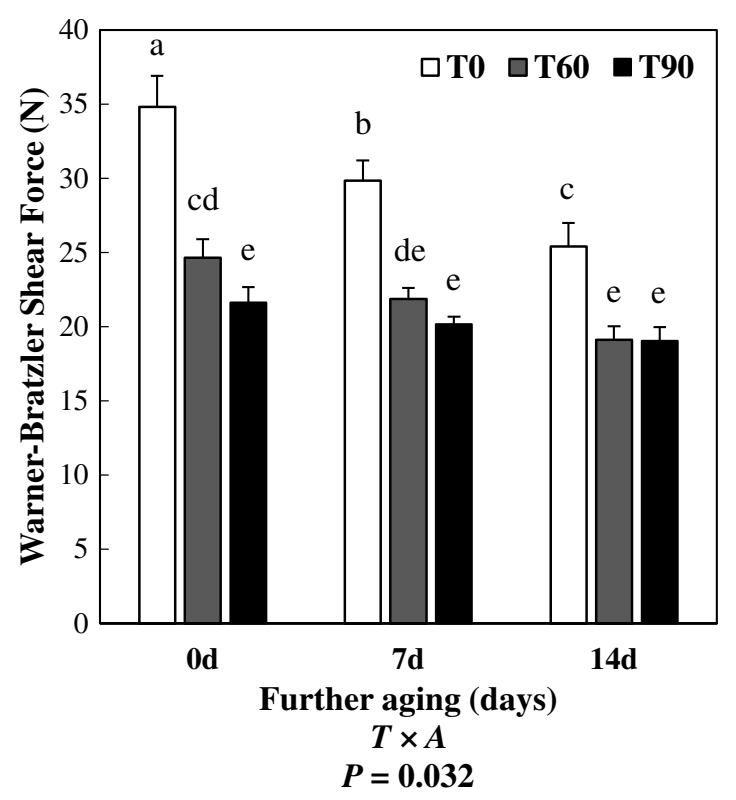

Figure 1. Interactive effect of fresh beef tumbling $(T)$ and further aging $(A)$ on Warner-Bratzler shear force values $(\mathrm{N})$ of beef loins $(n=9)$. Means lacking a common superscript (a-e) differ at $P<0.05$. Error bars indicate standard error of the mean. Note: T0 indicates nontumbled control, T60 indicates tumbled for $60 \mathrm{~min}$, and T90 indicates tumbled for $90 \mathrm{~min}$. decrease in WBSF values, decreasing from $34.8 \mathrm{~N}$ in T0 to $24.7 \mathrm{~N}$ and $21.6 \mathrm{~N}$ for T60 and T90 treatments, respectively. Although further aging decreased WBSF values of steaks from the control group $(P<0.05)$, the steaks from the T0 control group at $14 \mathrm{~d}$ further aging maintained higher WBSF values $(25.4 \mathrm{~N})$ than T90 immediately after tumbling $(P<0.05)$ and were comparable with the T60 group $(P>0.05)$. This result clearly indicates tumbling would have an immediate positive impact on instrumental tenderness, even without further aging. Further aging improved tenderness of the T60 steaks from 0 to $14 \mathrm{~d}(P<0.05)$, though no decrease in WBSF with aging was found in T90 $(P>0.05)$.

Multiple studies have found improved tenderness of tumbled meat products with an increase in tumbling duration (Dzudie and Okubanjo, 1999; Pietrasik and Shand, 2004; Moon et al., 2007), in particular with an increase in cumulative revolutions (Lin et al., 1990). However, considering the intermuscular differences regarding individual factors that influence tenderness (Rhee et al., 2004), it would be expected improvements to tenderness would be muscle-specific. Molina et al. (2005) evaluated the impacts of brine incorporation method (marinating, needle injection, or vacuum tumbling) on palatability attributes of 8 muscles from the beef chuck. It was found that tumbling could significantly reduce the amount of sensory detectable connective tissue in beef splenius and serratus ventralis muscles, though other muscles were not affected (Molina et al., 2005). Similarly, Morrow et al. (2019) found no positive effect of tumbling without brine on slice shear force values and consumer tenderness of beef rectus abdominus muscles. This may be attributed to the lower amount of cumulative revolutions $(20 \mathrm{~min}$ at $10 \mathrm{rpm}$ ) applied by Morrow et al. (2019) relative to the present study or by the inherent differences between the flank and loin muscles. The flank muscle has larger muscle fibers compared with the loin, as well as a larger amount of connective tissue (Jeremiah et al., 2003; Couvreur et al., 2019). It could also be expected that increased cooking loss through tumbling may result in poorer cooked meat tenderness (Warner, 2017; Warner et al., 2020), though Rhee et al. (2004) reported no correlation between cooking loss and WBSF values of the beef longissimus lumborum et thoracis. The present study is in agreement with this finding, as no correlation between WBSF and cooking loss was observed $(P=0.623$; Table 3$)$. A weak negative correlation $(\mathrm{r}=-0.34)$ was observed between WBSF and purge losses, which could be related to the degradation of sarcoplasmic proteins that are then more readily 
Table 3. Pearson correlation coefficients of various traits of beef loins

\begin{tabular}{lccccccc}
\hline \hline Trait $^{1}$ & COOK PURGE & MFI & TnT1 & TnT2 & DES1 & DES2 \\
\hline WBSF & 0.06 & $-0.34^{* *}$ & $-0.58^{* * *}$ & $0.38^{* *}$ & $-0.39^{* * *}$ & $0.35^{* *}$ & $-0.35^{* *}$ \\
COOK & & 0.00 & 0.15 & -0.15 & -0.08 & $0.25^{*}$ & -0.22 \\
PURGE & & & $0.58^{* * *}$ & $-0.36^{* * *}$ & 0.20 & $-0.34^{* *}$ & $0.34^{* *}$ \\
MFI & & & & $-0.54^{* * *}$ & $0.56^{* * *}$ & $-0.23^{*}$ & $0.42^{* * *}$ \\
TnT1 & & & & & -0.17 & $0.30^{* *}$ & -0.19 \\
TnT2 & & & & & & $-0.25^{*}$ & 0.19 \\
DES1 & & & & & & $-0.46^{* * *}$ \\
\hline
\end{tabular}

COOK = cooking loss; DES1 = desmin, intact; DES2 = desmin, degraded; $\mathrm{MFI}=$ myofibril fragmentation index; $\mathrm{PURGE}=$ purge loss; $\mathrm{TnT} 1=$ troponin $-\mathrm{T}, \quad$ intact; $\quad \mathrm{TnT} 2=$ troponin $-\mathrm{T}$, degraded; $\mathrm{WBSF}=$ Warner-Bratzler shear force.

${ }^{*} P<0.05$.

${ }^{* *} P<0.01$.

${ }^{* * *} P<0.001$.

expelled from the myofibrillar matrix (Purslow et al., 2016).

\section{Proteolysis and muscle ultrastructure}

MFI has been identified as a strong predictor of beef loin tenderness, regardless of animal maturity and intramuscular fat (Culler et al., 1978). The present study found moderate correlations between MFI values and WBSF $(r=-0.58)$, purge loss $(r=0.58)$, and relative abundances of intact $(\mathrm{r}=-0.54)$ and degraded $(\mathrm{r}=0.56)$ troponin- $\mathrm{T}(P<0.001$; Table 3$)$. Further, weak but significant correlations of MFI with intact $(\mathrm{r}=-0.23)$ and degraded $(\mathrm{r}=0.42)$ desmin were also observed. Both main effects of fresh beef tumbling and duration of postmortem aging influenced MFI values $(P<0.001 ;$ Figure 2A,B). Higher MFI values were observed in T60 (99.9) and T90 (104.0) compared with the T0 control group (93.1). This pattern was similar to that observed with aging duration, as $0 \mathrm{~d}(86.3)$ was lower than the $7 \mathrm{~d}$ (99.8) and $14 \mathrm{~d}$ (110.8) groups. Although both main effects of tumbling and aging were significant, the absolute differences between MFI were more pronounced between aging duration means. There was no interaction between fresh beef tumbling and aging for MFI $(P=0.366)$.

Although MFI was affected by both fresh beef tumbling and aging duration, the results of western blot analysis only partially agreed with the MFI results. This could be due to physical disruptions caused by tumbling resulting in fragmented myofibrils but not measurable proteolytic degradation. An interaction was observed in intact troponin-T $(P=0.009$; Figures 3 and $4 \mathrm{~B})$. Relative abundance was generally unchanged
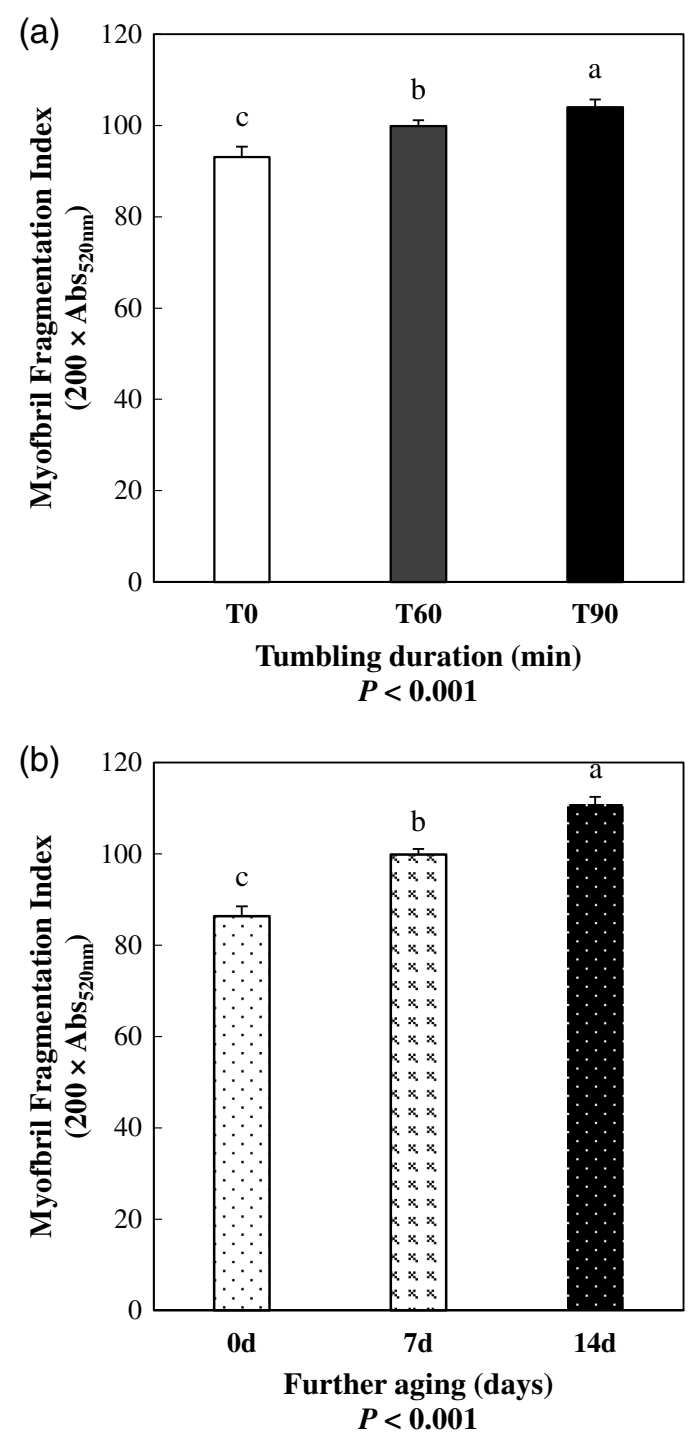

Figure 2. Main effects of fresh beef tumbling (A) and aging (B) on myofibril fragmentation index values of beef loins $(n=9)$. Means lacking a common superscript (a-c) differ at $P<0.05$. Error bars indicate standard error of the mean. The two-way interaction between fresh beef tumbling and aging duration was not significant $(P=0.366)$. Note: T0 indicates nontumbled control, T60 indicates tumbled for $60 \mathrm{~min}$, and T90 indicates tumbled for $90 \mathrm{~min}$.

across tumbling treatments at 0 and $7 \mathrm{~d}$, respectively. Less abundant intact troponin- $\mathrm{T}$ was observed in T90 at $14 \mathrm{~d}$, which could indicate a higher extent of proteolytic degradation through combined tumbling and aging treatment. Although an interaction of tumbling and aging was observed for intact troponin- $T$, only further aging affected relative abundances of intact desmin $(P=0.004$; Table 4 and Figure 4A), degraded desmin $(P<0.001$; Table 4 and Figure 4A), and degraded troponin-T $(P<0.001$; Table 4 and Figure 4B). Less intact desmin and more abundant desmin and troponin- $\mathrm{T}$ degradation products were observed at 7 and $14 \mathrm{~d}$ of further aging compared with $0 \mathrm{~d}$, whereas values between 7 and 


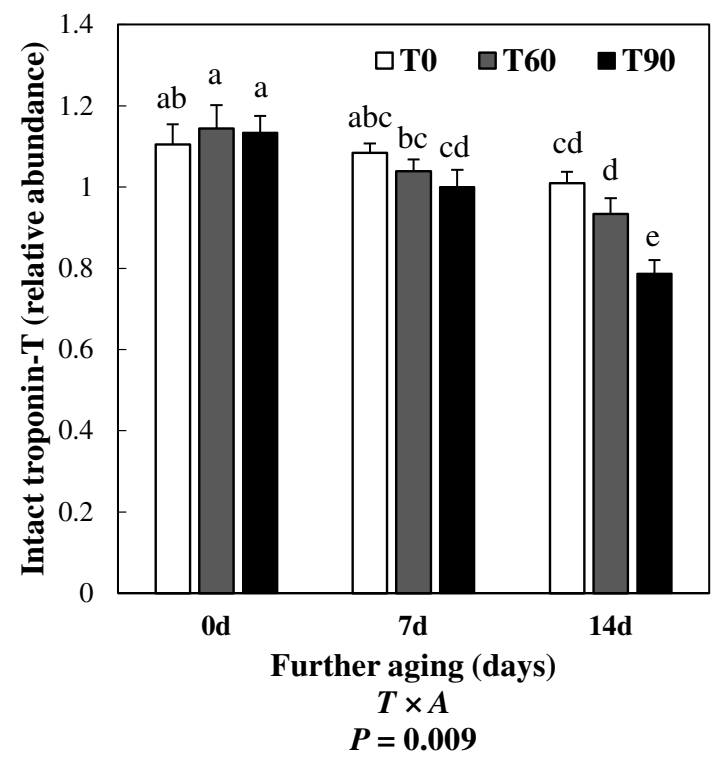

Figure 3. Interactive effect of fresh beef tumbling $(T)$ and further aging $(A)$ on relative abundance of intact troponin-T of beef loins $(n=9)$. Means lacking a common superscript (a-e) differ at $P<0.05$. Error bars indicate standard error of the mean. Bands were quantified by comparison of band intensity with the intact band of an internal reference sample (each same T0 control sample with $0 \mathrm{~d}$ further aging). Note: T0 indicates nontumbled control, T60 indicates tumbled for $60 \mathrm{~min}$, and T90 indicates tumbled for $90 \mathrm{~min}$.

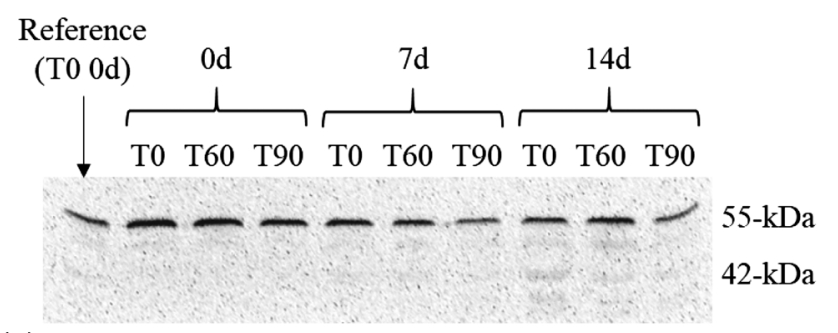

(a)

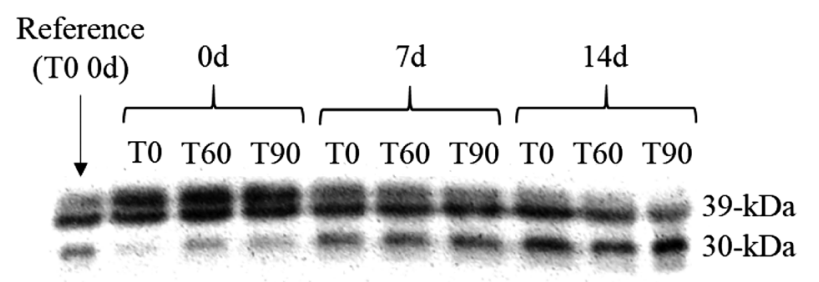

(b)

Figure 4. Representative western blot images of desmin (A) and troponin-T (B) from beef loins $(n=9)$ subjected to fresh beef tumbling and aging treatment. Note: T0 indicates nontumbled control, T60 indicates tumbled for $60 \mathrm{~min}$, and T90 indicates tumbled for $90 \mathrm{~min}$.

$14 \mathrm{~d}$ were comparable. As only intact troponin- $\mathrm{T}$ was affected by the interaction of tumbling and aging, it could be that tumbling would result in more proteolysis in the intercellular thin filament regions rather than intermediate filaments, adjacent myofibrils, and centromeric
Table 4. Effect of fresh beef tumbling and further aging on quantitative abundance of desmin (intact and degraded) and troponin-T (degraded) of beef loins $(n=9)$

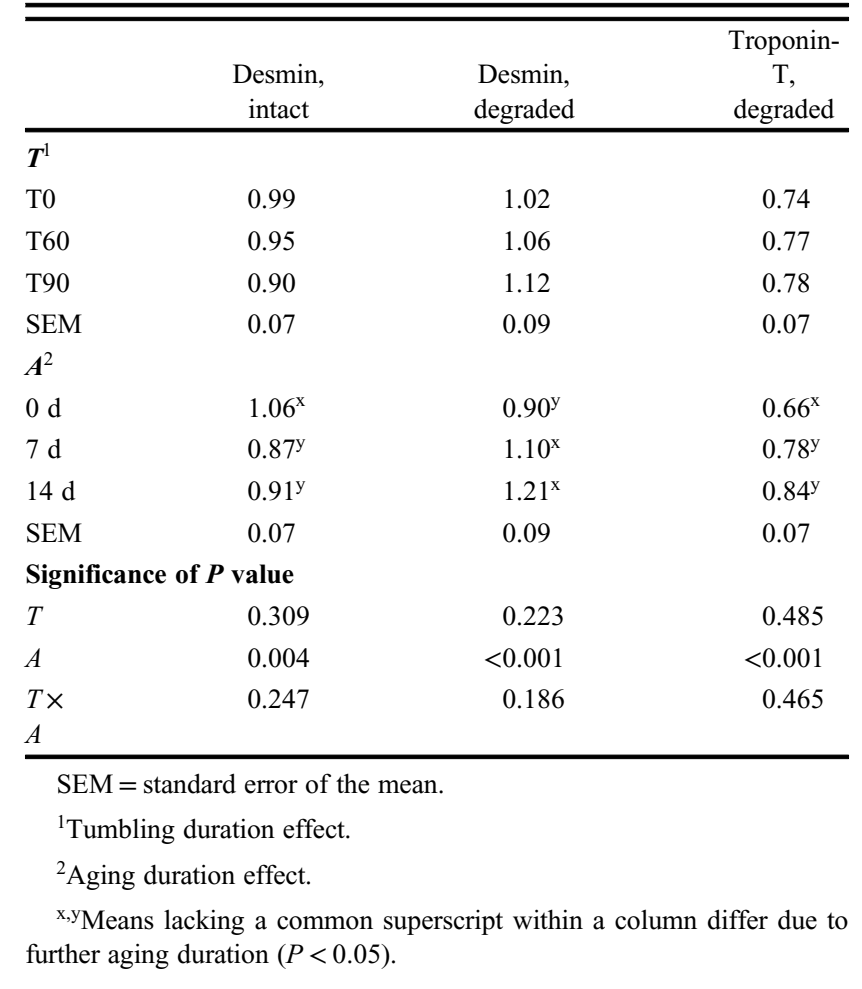

proteins. However, as multiple myofibrillar and cytoskeletal proteins are relevant to meat tenderness (Huff Lonergan et al., 2010; Kim et al., 2018b; Warner et al., 2020), further research into the potential effects of tumbling on proteolysis with aging would be necessary.

Representative TEM images of beef loin muscles across tumbling and further aging treatments are presented in Figure 5. As treatments were applied at $7 \mathrm{~d}$ postmortem, a loss of certain ultrastructural features including A and I bands was apparent in all samples. There was, in general, a limited effect of further aging on the ultrastructure of T0 control samples. Samples from T60 and T90 exhibited some lateral and longitudinal fracturing of the myofibrillar structure, although degradation of structures at the Z-line was generally similar to the respective T0 controls. Substantial degradation of the myofibrils, observed at both the Zline and myofibril itself, was apparent in the T60 and T90 groups with 7 and $14 \mathrm{~d}$ of further aging. This observation provides some support regarding the previously discussed measures of proteolysis. As fragmenting of the myofibrils occurred in the T60 and T90 groups at $0 \mathrm{~d}$ of further aging, the findings of increased MFI in tumbled treatments regardless of duration of postmortem aging would also be supported. 
Fresh beef tumbling duration ( $\mathrm{min})$

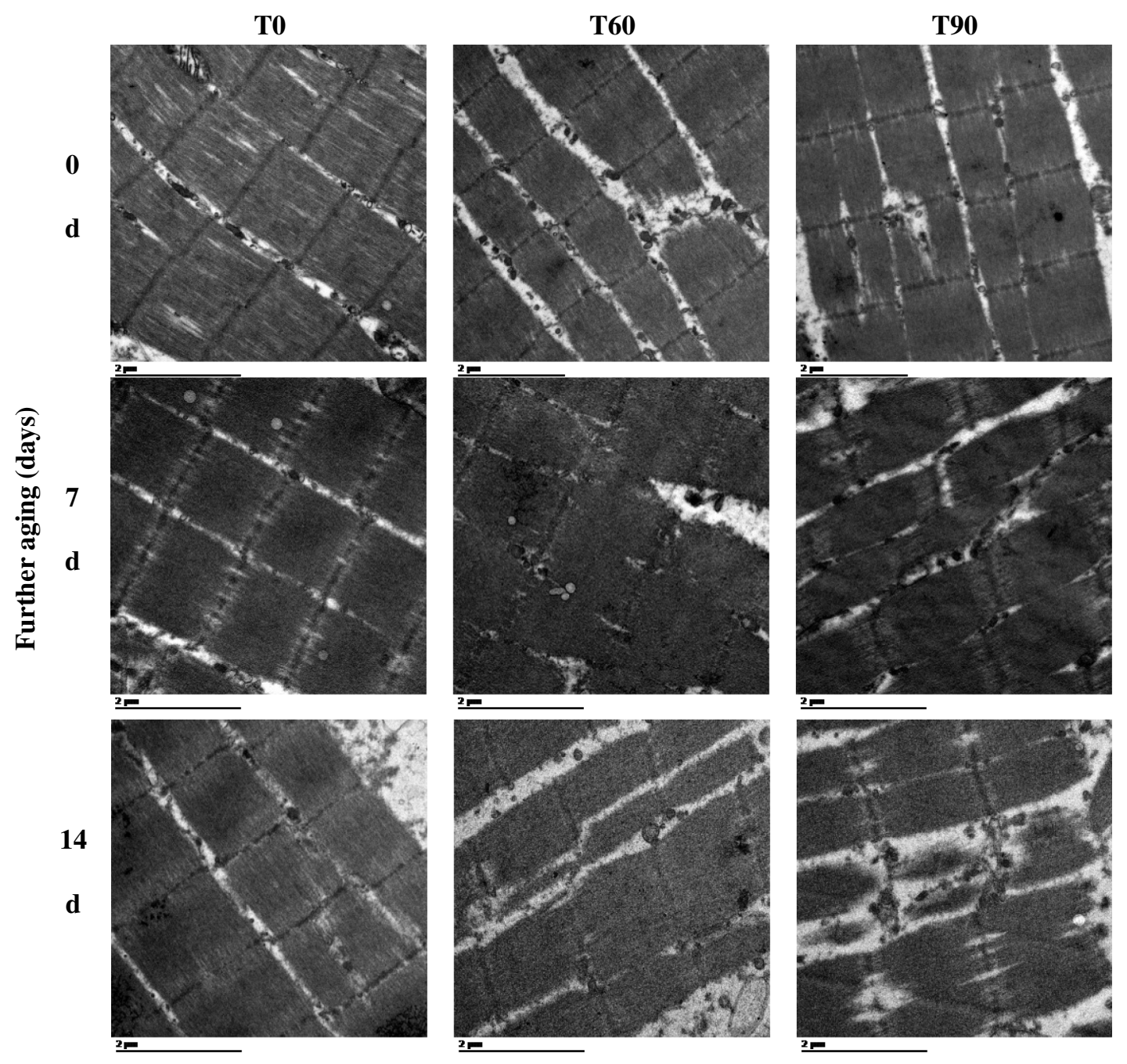

Figure 5. Representative transmission electron microscopy images (11,500 $\times$ magnification) of beef loin muscle ultrastructure by fresh beef tumbling and aging duration. Note: T0 indicates nontumbled control, T60 indicates tumbled for $60 \mathrm{~min}$, and T90 indicates tumbled for $90 \mathrm{~min}$.

\section{Conclusions}

This study supports that tumbling without a brine solution could be an effective strategy to improve objective tenderness of beef loin muscles. An additional $14 \mathrm{~d}$ of further aging was required for T0 loins to reach equivalent WBSF values to the T60 group achieved immediately after tumbling with no additional aging. Primarily, the effects of tumbling would be attributable to physical disruptions caused to the muscle structure, and no decrease in WBSF values with further aging was observed in the T90 group. These results provide some evidence that tumbling could result in increased proteolysis with aging. Although the added improvements to objective tenderness of tumbled beef loins with additional aging were negligible, these observations could be relevant to the tenderization of more inherently tough beef cuts. These findings could be utilized by the beef industry to achieve more consistent tenderness, which may eventually be applied to improve quality attributes of lower value cuts.

\section{Acknowledgements}

This work was supported in part by The Beef Checkoff and the US Department of Agriculture National Institute of Food and Agriculture, HatchMultistate project 1006773. The authors thank Dr. Chris Gilpin and Robert Seiler of the Whistler Life Science Microscope Facility for their assistance in TEM processing and imaging. 


\section{Literature Cited}

AMSA. 2012. Meat color measurement guidelines. American Meat Science Association, Champaign, IL.

AMSA. 2015. Section VIII. Instrumental measures of tenderness and textural properties. In: Research guidelines for cookery, sensory evaluation, and instrumental tenderness measurements of meat. American Meat Science Association, Champaign, IL. p. 82-85.

Boleman, S. J., S. L. Boleman, R. K. Miller, J. F. Taylor, H. R. Cross, T. L. Wheeler, M. Koohmaraie, S. D. Shackelford, M. F. Miller, R. L. West, D. D. Johnson, and J. W. Savell. 1997. Consumer evaluation of beef of known categories of tenderness. J. Anim. Sci. 75:1521-1524. https://doi.org/10. 2527/1997.7561521x.

Boles, J. A., and P. J. Shand. 2002. Tumbling regime effects on the processing characteristics and tenderness of cooked roast beef. J. Muscle Foods 13:25-35. https://doi.org/10.1111/j.17454573.2002.tb00318.x.

Bombrun, L., P. Gatellier, M. Carlier, and A. Kondjoyan. 2014. The effects of low salt concentrations on the mechanism of adhesion between two pieces of pork semimembranosus muscle following tumbling and cooking. Meat Sci. 96:5-13. https:// doi.org/10.1016/j.meatsci.2013.06.029.

Cheng, J., and H. W. Ockerman. 2003. Effect of phosphate with tumbling on lipid oxidation of precooked roast beef. Meat Sci. 65:1353-1359. https://doi.org/10.1016/S0309-1740(03) 00057-3.

Couvreur, S., G. Le Bec, D. Micol, and B. Picard. 2019. Relationships between cull beef cow characteristics, finishing practices and meat quality traits of longissimus thoracis and rectus abdominis. Foods 8:141. https://doi.org/10.3390/ foods 8040141.

Culler, R. D., F. C. Parrish, Jr., G. C. Smith, and H. R. Cross. 1978. Relationship of myofibril fragmentation index to certain chemical, physical and sensory characteristics of bovine longissimus muscle. J. Food Sci. 43:1177-1180. https://doi.org/ 10.1111/j.1365-2621.1978.tb15263.x.

Dzudie, T., and A. Okubanjo. 1999. Effects of rigor state and tumbling time on quality of goat hams. J. Food. Eng. 42:103-107. https://doi.org/10.1016/S0260-8774(99)00097-7.

Glover, E. E., J. C. Forrest, H. R. Johnson, V. D. Bramblett, and M. D. Judge. 1977. Palatability and cooking characteristics of mechanically tenderized beef. J. Food Sci. 42:871-874. https://doi.org/10.1111/j.1365-2621.1977.tb12626.x.

Gonzalez, J. M., and K. J. Phelps. 2018. United States beef quality as chronicled by the National Beef Quality Audits, Beef Consumer Satisfaction Projects, and National Beef Tenderness Surveys - A review. Asian Austral. J. Anim. 31:1036-1042. https://doi.org/10.5713/ajas.18.0199.

Guelker, M. R., A. N. Haneklaus, J. C. Brooks, C. C. Carr, R. J. Delmore, Jr., D. B. Griffin, D. S. Hale, K. B. Harris, G. G. Mafi, D. D. Johnson, C. L. Lorenzen, R. J. Maddock, J. N. Martin, R. K. Miller, C. R. Raines, D. L. VanOverbeke, L. L. Vedral, B. E. Wasser, and J. W. Savell. 2013. National Beef Tenderness Survey-2010: Warner-Bratzler shear force values and sensory panel ratings for beef steaks from United States retail and food service establishments. J.
Anim. Sci. 91:1005-1014. https://doi.org/10.2527/jas.20125785.

Huff Lonergan, E., W. Zhang, and S. M. Lonergan. 2010. Biochemistry of postmortem muscle - Lessons on mechanisms of meat tenderization. Meat Sci. 86:184-195. https:// doi.org/10.1016/j.meatsci.2010.05.004.

Jeremiah, L. E., L. L. Gibson, J. L. Aalhus, and M. E. R. Dugan. 2003. Assessment of palatability attributes of the major beef muscles. Meat Sci. 65:949-958. https://doi.org/10.1016/ S0309-1740(02)00307-8.

Jeremiah, L. E., L. L. Gibson, and B. Cunningham. 1999. The influence of mechanical tenderization on the palatability of certain bovine muscles. Food Res. Int. 32:585-591. https://doi. org/10.1016/S0963-9969(99)00134-9.

Juárez, M., I. L. Larsen, L. L. Gibson, W. M. Robertson, M. E. R. Dugan, N. Aldai, and J. L. Aalhus. 2010. Extended ageing time and temperature effects on quality of sub-primal cuts of boxed beef. Can. J. Anim. Sci. 90:361-370. https://doi. org/10.4141/CJAS09079.

Kim, H.-W., J.-H. Kim, J.-K. Seo, D. Setyabrata, and Y. H. B. Kim. 2018a. Effects of aging/freezing sequence and freezing rate on meat quality and oxidative stability of pork loins. Meat Sci. 139:162-170. https://doi.org/10.1016/j.meatsci.2018.01.024.

Kim, Y. H., S. M. Lonergan, and E. Huff-Lonergan. 2010. Protein denaturing conditions in beef deep semimembranosus muscle results in limited $\mu$-calpain activation and protein degradation. Meat Sci. 86:883-887. https://doi.org/10.1016/j.meatsci. 2010.06.002.

Kim, Y. H. B., D. Ma, D. Setyabrata, M. M. Farouk, S. M. Lonergan, E. Huff-Lonergan, and M. C. Hunt. 2018b. Understanding postmortem biochemical processes and postharvest aging factors to develop novel smart-aging strategies. Meat Sci. 144:74-90. https://doi.org/10.1016/j.meatsci.2018. 04.031

Lin, G. C., G. S. Mittal, and S. Barbut. 1990. Effects of tumbling speed and cumulative revolutions on restructured hams' quality. J. Food Process. Pres. 14:467-479. https://doi.org/10. 1111/j.1745-4549.1990.tb00147.x.

Luchansky, J. B., R. K. Phebus, H. Thippareddi, and J. E. Call. 2008. Translocation of surface-inoculated Escherichia coli O157:H7 into beef subprimals following blade tenderization. J. Food Protect. 71:2190-2197. https://doi.org/10.4315/0362028X-71.11.2190.

Martin, M. 2001. Meat curing technology. In: Y. H. Hui, W.-K. Nip, R. W. Rogers, and O. A. Young, editors. Meat Science and Applications. CRC Press, New York. p. 491508. https://doi.org/10.1201/9780203908082.

Martinez, H. A., A. N. Arnold, J. C. Brooks, C. C. Carr, K. B. Gehring, D. B. Griffin, D. S. Hale, G. G. Mafi, D. D. Johnson, C. L. Lorenzen, R. J. Maddock, R. K. Miller, D. L. VanOverbeke, B. E. Wasser, and J. W. Savell. 2017. National Beef Tenderness Survey-2015: Palatability and shear force assessments of retail and foodservice beef. Meat Muscle Biol. 1:138-148. https://doi.org/10.22175/mmb2017. 05.0028 .

McKillip, K. V., A. K. Wilfong, J. M. Gonzalez, T. A. Houser, J. A. Unruh, E. A. E. Boyle, and T. G. O'Quinn. 2017. Sensory evaluation of enhanced beef strip loin steaks cooked to 
3 degrees of doneness. Meat Muscle Biol. 1. https://doi.org/ 10.22175/mmb2017.06.0033.

Miller, R. 2020. Drivers of consumer liking for beef, pork, and lamb: A review. Foods 9:428. https://doi.org/10.3390/ foods 9040428.

Miller, M. F., M. A. Carr, C. B. Ramsey, K. L. Crockett, and L. C. Hoover. 2001. Consumer thresholds for establishing the value of beef tenderness. J. Anim. Sci. 79:3062-3068. https://doi. org/10.2527/2001.79123062x.

Molina, M. E., D. D. Johnson, R. L. West, and B. L. Gwartney. 2005. Enhancing palatability traits in beef chuck muscles. Meat Sci. 71:52-61. https://doi.org/10.1016/j.meatsci.2005. 04.004.

Moon, S. S., H. S. Yang, G. B. Park, and S. T. Joo. 2007. The effect of tumbling time on the quality and binding ability of restructured beef $M$. pectoralis profundus with alginate binder. Asian Austral. J. Anim. 20:418-423. https://doi.org/10.5713/ajas. 2007.418.

Morrow, S. J., A. J. Garmyn, N. C. Hardcastle, J. C. Brooks, and M. F. Miller. 2019. The effects of enhancement strategies of beef flanks on composition and consumer palatability characteristics. Meat Muscle Biol. 3:457-466. https://doi.org/10.22175/ mmb2019.07.0030.

Nair, M. N., A. C. V. C. S. Canto, G. Rentfrow, and S. P. Suman. 2019. Muscle-specific effect of aging on beef tenderness. LWT 100:250-252. https://doi.org/10.1016/j.lwt.2018.10. 038 .

Ockerman, H. W., R. F. Plimpton, Jr., V. R. Cahill, and N. A. Parrett. 1978. Influence of short term tumbling, salt and phosphate on cured canned pork. J. Food Sci. 43:878-881. https:// doi.org/10.1111/j.1365-2621.1978.tb02445.x.

O’Quinn, T. G., J. F. Legako, J. C. Brooks, and M. F. Miller. 2018. Evaluation of the contribution of tenderness, juiciness, and flavor to the overall consumer beef eating experience. Transl. Anim. Sci. 2:26-36. https://doi.org/10.1093/tas/ AQ1 txx008

Pearce, K. L., K. Rosenvold, H. J. Andersen, and D. L. Hopkins. 2011. Water distribution and mobility in meat during the conversion of muscle to meat and ageing and the impacts on fresh meat quality attributes — A review. Meat Sci. 89:111-124. https://doi.org/10.1016/j.meatsci.2011.04.007.

Pietrasik, Z., and P. J. Shand. 2004. Effect of blade tenderization and tumbling time on the processing characteristics and tenderness of injected cooked roast beef. Meat Sci. 66:871879. https://doi.org/10.1016/j.meatsci.2003.08.009.
Purslow, P. P., S. Oiseth, J. Hughes, and R. D. Warner. 2016. The structural basis of cooking loss in beef: Variations with temperature and ageing. Food Res. Int. 89:739-748. https://doi. org/10.1016/j.foodres.2016.09.010.

Rhee, M. S., T. L. Wheeler, S. D. Shackelford, and M. Koohmaraie. 2004. Variation in palatability and biochemical traits within and among eleven beef muscles. J. Anim. Sci. 82:534-550. https://doi.org/10.2527/2004.822534x.

Setyabrata, D., and Y. H. B. Kim. 2019. Impacts of aging/freezing sequence on microstructure, protein degradation and physicochemical properties of beef muscles. Meat Sci. 151:64-74. https://doi.org/10.1016/j.meatsci.2019.01.007.

Setyabrata, D., J. R. Tuell, and B. Kim. 2019. The effect of aging/ freezing sequence and freezing rate on quality attributes of beef loins. Meat Muscle Biol. 3:488-499. https://doi.org/10. $22175 / \mathrm{mmb} .11234$.

Shackelford, S. D., T. L. Wheeler, M. K. Meade, J. O. Reagan, B. L. Byrnes, and M. Koohmaraie. 2001. Consumer impressions of Tender Select beef. J. Anim. Sci. 79:2605-2614. https://doi. org/10.2527/2001.79102605x.

Suman, S. P., and P. Joseph. 2013. Myoglobin chemistry and meat color. Annu. Rev. Food Sci. T. 4:79-99. https://doi.org/10. 1146/annurev-food-030212-182623.

Voges, K. L., C. L. Mason, J. C. Brooks, R. J. Delmore, D. B. Griffin, D. S. Hale, W. R. Henning, D. D. Johnson, C. L. Lorenzen, R. J. Maddock, R. K. Miller, J. B. Morgan, B. E. Baird, B. L. Gwartney, and J. W. Savell. 2007. National beef tenderness survey - 2006: Assessment of Warner-Bratzler shear and sensory panel ratings for beef from US retail and foodservice establishments. Meat Sci. 77:357-364. https:// doi.org/10.1016/j.meatsci.2007.03.024.

Warner, R. D. 2017. Chapter 14 - The eating quality of meat-IV water-holding capacity and juiciness. In: F. Toldrá, editor, Lawrie's meat science (eighth edition). Woodhead Publishing, Cambridge, UK. p. 419-459. https://doi.org/10. 1016/B978-0-08-100694-8.00014-5.

Warner, R., R. Miller, M. Ha, T. L. Wheeler, F. Dunshea, X. Li, R. Vaskoska, and P. Purslow. 2020. Meat tenderness: underlying mechanisms, instrumental measurement, and sensory assessment. Meat Muscle Biol. 4:17, 1-25. https://doi.org/10. 22175/mmb. 10489

Yang, L., N. L. Arnold, T. Drape, R. C. Williams, T. Archibald, B. Chapman, and R. Boyer. 2021. A survey of United States consumer awareness, purchasing, and handling of mechanically tenderized beef products. Food Control. 120:107505. https://doi.org/10.1016/j.foodcont.2020.107505. 